\title{
Silver Nanoparticles Attenuate the Antimicrobial Activity of the Innate Immune System by Inhibiting Neutrophil-Mediated Phagocytosis and Reactive Oxygen Species Production
}

This article was published in the following Dove Press journal:

International Journal of Nanomedicine

\author{
Moran Huang $\mathbb{D}^{1, *}$ \\ Kai $\mathrm{Ye}^{\mathrm{l}, *}$ \\ $\mathrm{Tu} \mathrm{Hu}^{2, *}$ \\ Kexin Liu $^{3}$ \\ Mengzhen You $^{3}$ \\ Lei Wang' \\ Hui Qin (D) \\ 'Department of Orthopaedics, Shanghai \\ Jiaotong University Affiliated Sixth \\ People's Hospital, Shanghai, People's \\ Republic of China; ${ }^{2}$ Department of \\ Musculoskeletal Surgery, Fudan \\ University Shanghai Cancer Center, \\ Shanghai, People's Republic of China; \\ ${ }^{3}$ Department of General Practice, \\ Shanghai Jiaotong University Affiliated \\ Sixth People's Hospital, Shanghai, People's \\ Republic of China
}

*These authors contributed equally to this work

\begin{abstract}
Purpose: Despite the extensive development of antibacterial biomaterials, there are few reports on the effects of materials on the antibacterial ability of the immune system, and in particular of neutrophils. In this study, we observe differences between the in vivo and in vitro anti-infective efficacies of silver nanoparticles (AgNPs). The present study was designed to further explore the mechanism for this inconsistency using ex vivo models and in vitro experiments.
\end{abstract}

Methods: AgNPs were synthesized using the polyol process and characterized by transmission electron microscopy and X-ray photoelectron spectroscopy. The antibacterial ability of AgNPs and neutrophils was tested by the spread-plate method. The infected air pouch model was prepared to detect the antimicrobial ability of AgNPs in vivo. Furthermore, blood-AgNPsbacteria co-culture model and reactive oxygen species (ROS) measurement were used to evaluate the effect of AgNPs to neutrophil-mediated phagocytosis and ROS production.

Results: The antibacterial experiments in vitro showed that AgNPs had superior antibacterial properties in cell compatible concentration. While, AgNPs had no significant antibacterial effect in vivo, and pathological section in AgNPs group indicated less neutrophil infiltration in inflammatory site than $S$. aureus group. Furthermore, AgNPs were found to reduce the phagocytosis of neutrophils and inhibit their ability to produce ROS and superoxide during ex vivo and in vitro experiments.

Conclusion: This study selects AgNPs as the representative of inorganic nano-biomaterials and reveals the phenomenon and the mechanism underlying the significant AgNPs-induced inhibition of the antibacterial ability of neutrophils, and may have a certain enlightening effect on the development of biomaterials in the future. In the fabrication of antibacterial biomaterials, however, attention should be paid to both cell and immune system safety to make the antibacterial properties of the biomaterials and innate immune system complement each other and jointly promote the host's ability to resist the invasion of pathogenic microorganisms.

Keywords: antibacterial biomaterials, polymorphonuclear neutrophils, silver nanoparticles, immune system

\section{Introduction}

The infection of orthopedic implants, including open reduction and internal fixation of fractures (ORIF) and periprosthetic joint infection (PJI), is a common clinical complication, which may lead to implant failure and relapse, with a rate as high as $2 \%-5 \%{ }^{1,2}$ Implant infections are not only a heavy burden on the quality of life of patients but also constitute a huge economic burden on individuals and society. ${ }^{3}$
Correspondence: Hui Qin; Lei Wang jiaotong University Affiliated Sixth People's Hospital, No. 600 Yishan Road, Shanghai, People's Republic of China

Tel +86-|35-64| 43033 ; +86- I89-

30172609

Fax +862I-6470-|36|

Email qh197826@163.com;

wanglei2264@I26.com
International Journal of Nanomedicine 2021:16 1345-1360

1345

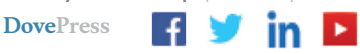

http://doi.org/10.2147/IJN.\$292482 
Furthermore, in recent years, with the prevalence of multidrug-resistant (MDR) strains, there is no doubt that traditional antibiotic treatment is limited. ${ }^{4}$

As a solution to the antibiotic resistance problem, inorganic antibacterial agents, including silver, ${ }^{5}$ cooper, ${ }^{6}$ gold, ${ }^{7}$ zinc $^{8}$ and their nanoparticles, which have good chemical stability and are not associated with drug resistance, have emerged as alternatives to antibiotics. These antibacterial agents and the development and fabrication of more effective antibacterial biomaterials have attracted wide attention from researchers worldwide. However, these antimicrobial agents often have poor biocompatibility, which can cause cytotoxicity at very low concentrations ${ }^{9}$ and inhibit the immune function of the host. $^{10,11}$ This is disadvantageous for the prevention of infection. In view of this, it is necessary to develop safer methods for antibacterial functionalization of implant surfaces.

Upon biomaterial implantation into the body, the host immune system initiates a series of responses, including the rapid adhesion of proteins in blood or tissue fluid to the surface of the implant and the activation of surrounding immune cells. ${ }^{12,13}$ As a key component of the host immune system, ${ }^{14}$ polymorphonuclear neutrophils (PMNs) migrate to the inflammatory site to engulf and kill pathogens when pathogenic microorganisms invade the host. ${ }^{15}$ Neutrophils exhibit superior antibacterial activity through their unique inherent properties, including phagocytosis, production of reactive oxygen species (ROS), degranulation, and formation of extracellular trapping networks (NETs). ${ }^{16,17}$ Furthermore, neutrophils play a crucial role in the recruitment of other immune cells to the infected site by releasing chemokines and cytokines. ${ }^{18}$ These processes are activated in the presence of foreign bodies such as implants. With sustained stimulation, the neutrophils in the surrounding vessels are continuously recruited, leading to the secretion of higher concentrations of proteolytic enzymes and ROS production, which aggravate the local inflammatory response causing tissue damage at the implantation site. ${ }^{19,20}$ Thus, the immune response of the host to the implant directly determines the success or failure of the implant, and the external intervention that can effectively affect the antibacterial properties of neutrophils is bound to further influence the host's ability to resist pathogen invasion. ${ }^{21-23}$ In other words, it is necessary to explore the effects of biomaterials with good antibacterial activity or potential on immune cells, and particularly on neutrophils. That is, in addition to cellular safety, "the immune system safety" of biomaterials is equally important.

As inorganic metal nanoparticles possessing the unique properties of small size and high surface area to volume ratio, AgNPs are widely used in the fabrication and modification of orthopedic biomaterials because of their superior broad-spectrum antibacterial capability and their ability to reduce microbial resistance. ${ }^{24-26}$ Previous studies have focused solely on the interaction between biomaterials and bacteria. ${ }^{5,24,27}$ Although some articles have studied the effects of silver nanoparticles on the biological characteristics of neutrophils, ${ }^{11,28,29}$ they have not systematically examined the antibacterial properties of silver nanoparticles in vivo and in vitro and the phenomenon of their interaction with bacteria and neutrophils, especially on the underlying mechanism.

In this study, we explored the effects of AgNPs on the antimicrobial ability of neutrophils in vitro in the presence of bacteria and constructed a rat infected air pouch model to explore its effect on the host's anti-infection ability in vivo (Figure 1). Furthermore, we established immune cell-bacteria-AgNPs coculture ex vivo models (Figure 2) to study the potential influence of AgNPs on host immunity.

\section{Materials and Methods Synthesis of AgNPs}

Twenty milliliters of glycol were placed in a three-port flask and heated to a specified temperature by placing it in a silicone oil bath, while stirring using magnetic force. Then, $10 \mathrm{~mL}$ of $0.1 \mathrm{~mol} / \mathrm{L} \mathrm{AgNO3} \mathrm{glycol} \mathrm{solution} \mathrm{was}$ added to the above preheated glycol solution. $\mathrm{AgNO}_{3}$ was obtained from Maoguo Nano Technology Co, Ltd (Shanghai, China). Next, the PVPK30 glycol solution was slowly dripped into the above solution (completed in 5 min). Finally, the product was transferred into a centrifuge tube and washed with anhydrous ethanol, before it was centrifuged and separated at $8000 \mathrm{rpm}$ for $10 \mathrm{~min}$ in a high-speed centrifuge 4-5 times to remove the PVP adsorbed on the surface.

\section{Characterization of the Silver Nanoparticles}

Transmission electron microscopy (TEM) (JEOL JSMIT200, Japan) was used to observe the particle size and morphology, while the chemical element composition and state of AgNPs were measured by X-ray 


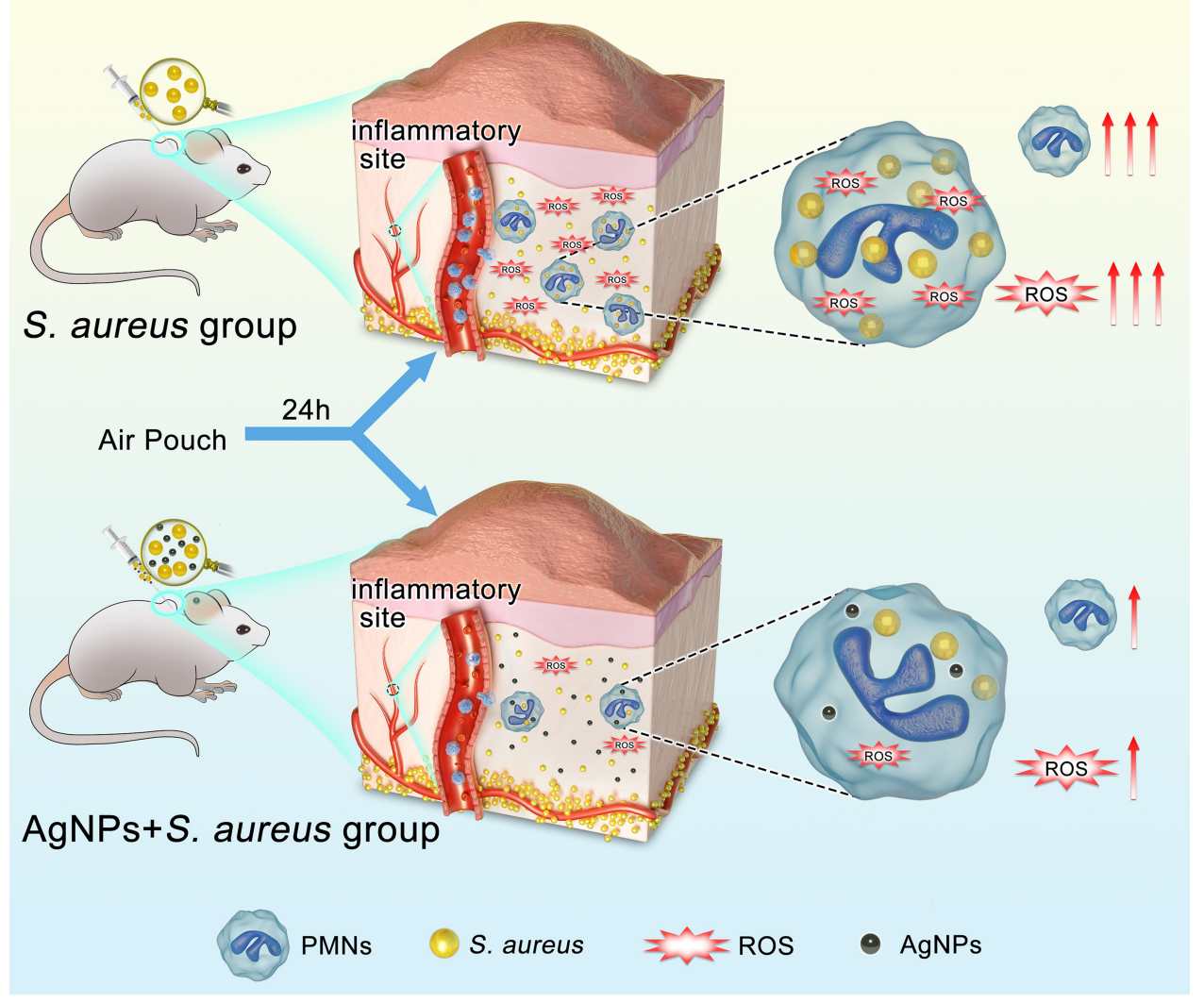

Figure I Schematic illustration of AgNPs inhibition to the antibacterial behavior of PMNs.

photoelectron spectroscopy (XPS; Thermo Scientific Escalab 250Xi, US).

\section{Isolation of Human PMNs}

Before venous blood collection from each volunteer, a standard protocol was approved by the Ethics Committee of Shanghai Jiaotong University Affiliated Sixth People's Hospital (Approval No: 2020-KY-118 $(\mathrm{K})$ ), and informed consent was obtained from each healthy adult volunteer, and this study was conducted in accordance with the Declaration of Helsinki. PMNs were isolated from the heparinized venous blood using a human peripheral blood neutrophil separation kit (Solarbio, Beijing, China). Trypan blue staining was used to ensure the activity of the isolated neutrophils.

\section{In vitro Cytotoxicity Evaluation}

PMNs $\left(5 \times 10^{5}\right.$ cells per well) were incubated with various concentrations $(0.5 \mu \mathrm{g} / \mathrm{mL}, 1 \mu \mathrm{g} / \mathrm{mL}, 2 \mu \mathrm{g} / \mathrm{mL}$, and $4 \mu \mathrm{g} /$ $\mathrm{mL}$ ) of AgNPs in complete RPMI 1640 medium (HyClone, USA) for $4 \mathrm{~h}$. Then, the co-culture medium of each well was replaced with $0.1 \mathrm{~mL}$ of serum-free RPMI 1640 medium containing $10 \mu \mathrm{L}$ of CCK-8 solution (Dojindo Kagaku Co, Kumamoto, Japan), followed by incubation for $1 \mathrm{~h}$. Next, the absorbance of the incubated solution system was determined at $450 \mathrm{~nm}$ using a microplate reader (Thermo Scientific, USA). Furthermore, lactate dehydrogenase (LDH) assays were used to determine the cellular activity of PMNs using the LDH cytotoxicity kit (Beyotime, Shanghai, China) according to the manufacturer's protocol. In addition, after coculture with AgNPs for $4 \mathrm{~h}$, PMNs were fixed with $4 \%$ paraformaldehyde for $10 \mathrm{~min}$ and permeabilized with $0.1 \%$ Triton-X for $5 \mathrm{~min}$, and then stained with TRITC-phalloidin and Dapi (Servicebio, Wuhan, China) for 30 and $10 \mathrm{~min}$, respectively. Fluorescent images were obtained using a fluorescence microscope (Leica, Hamburg, Germany).

\section{Preparation and Characterization of Bacteria}

In this study, gram-positive Staphylococcus aureus (S. aureus) (ATCC 43300) was obtained from the American Type Culture Collection (Rockefeller, MD) in 


\section{S. aureus group}

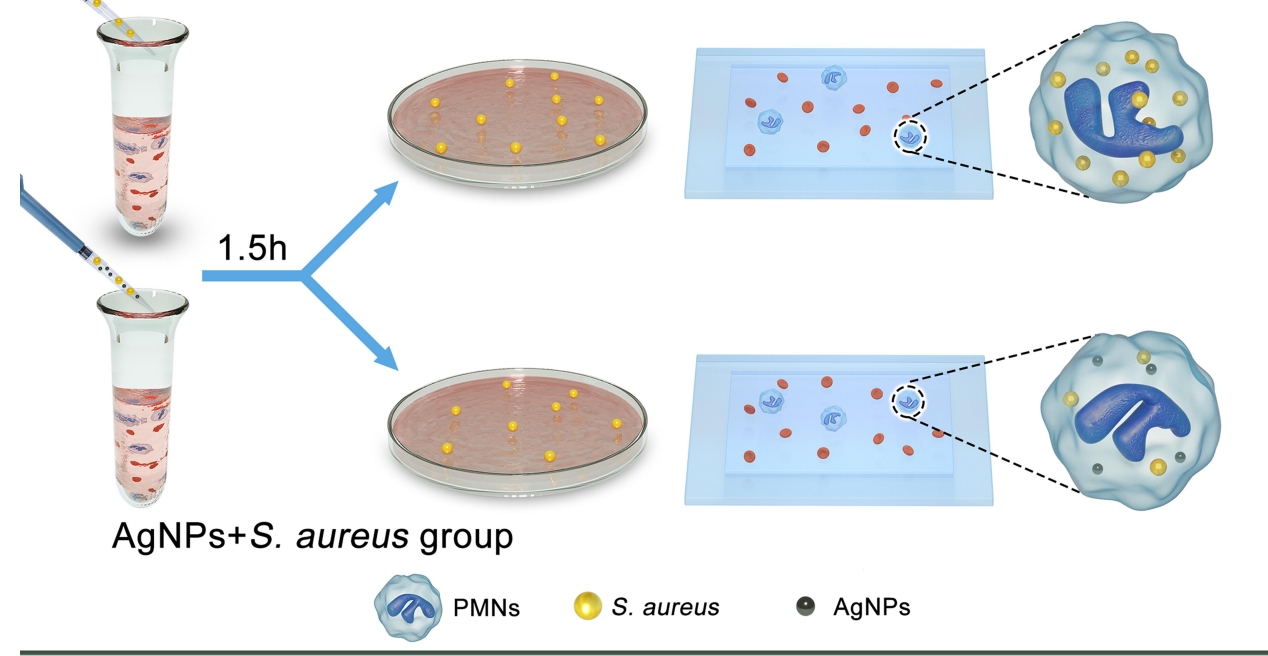

Figure 2 Schematic illustration of ex vivo experiment.

freeze-dried form. The bacteria were cultured on sheep blood agar (SBA) plates at $37{ }^{\circ} \mathrm{C}$ overnight. Then, a single bacterial colony was carefully transferred to $3 \mathrm{~mL}$ of TSB and incubated on an orbital shaker for another $12 \mathrm{~h}$. The purified bacterial solution was gradient diluted to a suitable concentration for in vitro and in vivo experiments.

\section{In vitro Antibacterial Ability of AgNPs and Antibacterial Capability of PMNs Treated by $\mathrm{AgNPs}$}

After a single bacterial colony was incubated overnight, the bacterial suspension was diluted to a concentration of $1 \times 10^{5}$ $\mathrm{CFU} / \mathrm{mL}$ and used to perform in vitro antimicrobial experiments. One milliliter of bacterial fluid $\left(1 \times 10^{5} \mathrm{CFU} / \mathrm{mL}\right)$ was incubated with different concentrations $(0.5 \mu \mathrm{g} / \mathrm{mL}, 1 \mu \mathrm{g} / \mathrm{mL}$, and $2 \mu \mathrm{g} / \mathrm{mL}$ ) of AgNPs in a 24-well plate in a bacteriological incubator for $4 \mathrm{~h}$. Afterwards, the spread-plate method ${ }^{30}$ was used to evaluate the survival rates of bacteria in each group, and the bacteria count was further expressed as $\log _{10} \mathrm{CFU}$. To investigate if the antibacterial ability of human PMNs was affected by AgPNs, $1 \mathrm{~mL}$ of $10^{5}$ cells/mL PMNs was added to 24-well plates and pretreated with different concentrations $(0 \mu \mathrm{g} / \mathrm{mL}, 0.5 \mu \mathrm{g} / \mathrm{mL}, 1 \mu \mathrm{g} / \mathrm{mL}$, and $2 \mu \mathrm{g} / \mathrm{mL})$ of AgNPs for 2 $\mathrm{h}$, the mixed system containing PMNs and AgNPs was collected and centrifuged, the supernatant was then removed. PMNs were then resuscitated by $900 \mu \mathrm{L}$ PBS and mixed with $100 \mu \mathrm{L}$ of $1 \times 10^{6} \mathrm{CFU} / \mathrm{mL}$ bacterial suspension, the gradient dilution and the spread-plate method were used to count bacteria and calculate the number of planktonic bacteria.

\section{In vivo Air Pouch Model Preparation}

All animal experiments were approved by the Animal Care and Ethics Committee of Shanghai Jiaotong University Affiliated Sixth People's Hospital (Approval No: DWLL2020-0614) and carried out in accordance with the guidelines for the care and use of laboratory animals. S. aureus-infected air pouches were established in 2-month-old female Sprague-Dawley (SD) rats. Before the operation, the rats were anesthetized using an intraperitoneal injection of pentobarbital, followed by shaving and sterilizing the skin of the air pouch. To establish the air pouch model, $20 \mathrm{~mL}$ sterilized air was subcutaneously injected into the backs of the rats at day 0 and $10 \mathrm{~mL}$ at day 3. Subsequently, the rats were divided into four groups $(\mathrm{n}=8)$ : control group, $1 \mu \mathrm{g} / \mathrm{mL}$ $\mathrm{AgNPs}+S$. aureus group, $2 \mu \mathrm{g} / \mathrm{mL} \mathrm{AgNPs}+S$. aureus group, and $S$. aureus group. Then, Aseptic saline and $1 \times 10^{7} \mathrm{CFU} / \mathrm{mL}$ bacterial solution alone or together with either $1 \mu \mathrm{g} / \mathrm{mL}$ AgNPs or $2 \mu \mathrm{g} / \mathrm{mL}$ AgNPs were subcutaneously injected into the air pouch in a total volume of $2 \mathrm{~mL}$, and the rats were observed for $24 \mathrm{~h}$.

\section{In vivo Antibacterial Assessment}

To investigate the antibacterial ability of AgNPs in vivo, $24 \mathrm{~h}$ after the air pouch model was established, five rats of 
each group were euthanized, and the tissue around the air pouch was aseptically cut off, weighed, and then collected using $1 \mathrm{~mL}$ of sterile PBS. Subsequently, the tissue was snap frozen, pulverized under sterile conditions, and, then, tissue homogenates were prepared to calculate the number of bacteria in each group using the spread-plate method.

\section{Cytokine Level Measurement in in vivo Lavage Fluid}

Before three rats in each group were sacrificed, the air pouch was injected and rinsed with $5 \mathrm{~mL}$ of sterile PBS, and then, the cytokine levels in the collected lavage fluid were measured using ELISA kits (Antigenix, USA).

\section{Histological Evaluation}

After three rats in each group were sacrificed, the tissue consisting of the air pouch and surrounding soft tissue was cut off, imaged, and fixed with $10 \%$ formalin. The specimens were then gradient dehydrated with ethanol and embedded in paraffin. Sections, obtained using a sledge microtome (Leica, Hamburg, Germany), were stained with hematoxylin and eosin (H\&E) and Giemsa staining. Inflammatory cell infiltration and bacterial infection were observed using optical microscopy (Nikon, Japan).

\section{Blood-AgNPs-Bacteria Co-Culture Model}

To establish the blood-AgNPs-bacteria co-culture model, ${ }^{31}$ $500 \mu \mathrm{L}$ of heparinized venous blood was mixed gently with $S$. aureus $\left(1 \times 10^{7} \mathrm{CFU} / \mathrm{mL}\right)$ at a ratio of $9: 1$, and various concentrations $(0 \mu \mathrm{g} / \mathrm{mL}, 0.5 \mu \mathrm{g} / \mathrm{mL}, 1 \mu \mathrm{g} / \mathrm{mL}$, and $2 \mu \mathrm{g} / \mathrm{mL}$ ) of AgNPs. Then, the mixtures were added to the wells of a sterile 24-well plate and were incubated at $37{ }^{\circ} \mathrm{C}$ for $90 \mathrm{~min}$. To investigate the survival rates of bacteria in the mixture, after coculture for $90 \mathrm{~min}$, the spread-plate method was used to calculate the viable bacteria in each experimental group, which was expressed as $\log _{10}$ CFU. To further detect PMN phagocytosis in human blood, blood smears were prepared at each designated coculture time point $(0,15,30,60$, and $90 \mathrm{~min})$, stained with Wright-Giemsa stain and observed using optical microscopy. Furthermore, to quantitatively evaluate the phagocytic ability of PMNs, the number of phagocytosed bacteria, bound bacteria, and free bacteria within a $10 \mu \mathrm{m}$ radius of each PMN were counted in six independent microscopic fields. The phagocytosis rate $(\%)=$ (phagocytosed bacteria count/total phagocytosed bacteria, bound bacteria, and free bacteria) $\times 100$.

\section{Isolated Human Neutrophil-AgNPs- Bacteria Coculture Model}

Isolated PMNs were cocultured with different dosages ( 0.5 $\mu \mathrm{g} / \mathrm{mL}, 1 \mu \mathrm{g} / \mathrm{mL}$, and $2 \mu \mathrm{g} / \mathrm{mL}$ ) of AgNPs and $1 \times 10^{7}$ $\mathrm{CFU} / \mathrm{mL}$ bacteria. After incubation for $2 \mathrm{~h}$, the PMN lysis rate of each group was measured using the LDH cytotoxicity kit (Beyotime, Shanghai, China) as mentioned above.

\section{The Effect of AgNPs on Human PMNs ROS Production}

Fluorescence detection of ROS was performed using the Reactive Oxygen Species Assay Kit (Beyotime, Shanghai, China). Different concentrations of AgNPs $(0.5 \mu \mathrm{g} / \mathrm{mL}, 1$ $\mu \mathrm{g} / \mathrm{mL}$ and $2 \mu \mathrm{g} / \mathrm{mL}$ ) were incubated with $0.5 \mathrm{~mL}$ of $10^{5}$ cells $/ \mathrm{mL}$ PMNs and $50 \mu \mathrm{L}$ of $1 \times 10^{7} \mathrm{CFU} / \mathrm{mL}$ bacterial suspension in a 24-well plate for $1.5 \mathrm{~h}$. Next, 2-7-dichlorodiacetate (DCFH-DA) fluorescent dye diluted in PBS was added to each plate and stained for $30 \mathrm{~min}$. Then, the cells were washed with PBS three times, followed by fixation with $4 \%$ paraformaldehyde for $10 \mathrm{~min}$. The fluorescence produced by the cells was observed using an inverted fluorescence microscope, and fluorescence quantification was detected using a fluorescence microplate reader (Thermo Scientific, USA).

\section{The Effect of AgNPs on the Production of Superoxide by Human PMNs}

Superoxide production in each group was detected using a superoxide assay kit (Beyotime, Shanghai, China). Briefly, $1 \times 10^{5}$ PMNs were suspended in $0.2 \mathrm{~mL}$ of superoxide detection working liquid and incubated with different AgNP concentrations $(0.5 \mu \mathrm{g} / \mathrm{mL}, 1 \mu \mathrm{g} / \mathrm{mL}$ and $2 \mu \mathrm{g} /$ $\mathrm{mL}$ ) and $10 \mu \mathrm{L}$ of $1 \times 10^{7} \mathrm{CFU} / \mathrm{mL}$ bacterial suspension in a 96-well plate for $2 \mathrm{~h}$. Then, the absorbance of each cultured system was measured at $450 \mathrm{~nm}$.

\section{The Effect of AgNPs on Human PMNs Migration}

Briefly, $10^{5} \mathrm{PMNs} / \mathrm{mL}$ suspended in $0.2 \mathrm{~mL}$ complete RPMI 1640 medium were added to the upper chamber of a 24-well transwell plate (Corning, USA; pore size $=3$ $\mu \mathrm{m})$, and then $0.5 \mathrm{~mL}$ complete RPMI 1640 medium containing different concentrations of AgNPs and $1 \times 10^{6}$ $\mathrm{CFU} / \mathrm{mL}$ bacterial solution was added into the lower chamber. After incubation for $2 \mathrm{~h}$, the cells on the upper 
surface of the membrane were gently removed via a cotton swab, and the cells that migrated to the lower surface of the membrane were first fixed with $4 \%$ paraformaldehyde and then stained with $0.5 \%$ crystal violet for $10 \mathrm{~min}$.

\section{The Effect of AgNPs on Human PMNs Cytokine Production}

PMNs $\left(1 \mathrm{~mL}\right.$ of $1 \times 10^{6}$ cells $\left./ \mathrm{mL}\right)$ were incubated with different concentrations of AgNPs $(0.5 \mu \mathrm{g} / \mathrm{mL}, 1 \mu \mathrm{g} / \mathrm{mL}$ and $2 \mu \mathrm{g} /$ $\mathrm{mL}$ ) and $0.1 \mathrm{~mL}$ of $1 \times 10^{7} \mathrm{CFU} / \mathrm{mL}$ bacterial suspension for 4 $\mathrm{h}$ in 24 well plates, and then, the culture medium was collected, and centrifuged. The supernatants were extracted, and the cytokine levels, including those of IL-1 $\beta$, IL-6, and MCP1, were measured using ELISA kits (Anogen, Canada).

\section{Quantitative Real-Time PCR (RT-PCR)}

\section{Analysis}

PMNs $\left(1 \mathrm{~mL}\right.$ of $3 \times 10^{6}$ cells $\left./ \mathrm{mL}\right)$ were cocultured with various concentrations of AgNPs $(0.5 \mu \mathrm{g} / \mathrm{mL}, 1 \mu \mathrm{g} / \mathrm{mL}$, and $2 \mu \mathrm{g} / \mathrm{mL}$ ) and $0.1 \mathrm{~mL}$ of $1 \times 10^{7} \mathrm{CFU} / \mathrm{mL}$ bacterial suspension for $4 \mathrm{~h}$, centrifuged, and washed twice with PBS. The EZ-press RNA Purification Kit (EZBioscience, USA) was used for total RNA extraction after a 5-min incubation on ice. Subsequently, the extracted total RNA was reverse-transcribed into cDNA by using a $4 \times$ Reverse Transcription Master Mix (EZBioscience, USA) according to the standard protocol. RT-qPCR experiments were performed using the EZBioscience $2 \times$ SYBR Green $q P C R$ Master Mix and the Q7 Real-Time PCR System (Applied Biosystems, USA). The following primer sequences were used: IL-6 (forward: 5'-AACAACCTGAAC CTTCCAAAG-3', reverse: 5'-CAAACTCCAAAAG ACCAGTGA-3'), TNF- $\alpha$ (forward: 5'-CAGGACTTG AGAAGACCTCAC-3', reverse: 5'-GTCTGGAAAC ATCTGGAGAGA-3'), IL-1 $\beta$ (forward: 5'-GATAT GGAGCAACAAGTGGT-3', reverse: 5'-AGGACAG GTACAGATTCT TTTC-3').

\section{Statistical Analysis}

The data from in vitro and in vivo experiments were expressed as the mean \pm standard deviation. One-way ANOVA was used to evaluate the statistical significance of the results (GraphPad Prism5, La Jolla, CA), and a $P$ value of $<0.05$ was considered statistically significant.

\section{Results}

\section{Characterization of AgNPs}

The morphology of AgNPs was examined using TEM analysis, and the results shown in Figure 3A, demonstrated that AgNPs were spherical in shape with an effective diameter of $17.9 \pm 7.8 \mathrm{~nm}$, and the size distribution was analyzed by counting more than 300 nanoparticles and indicated in Figure 3B. X-ray photoelectron spectroscopy of AgNPs was shown in Figure 3C and D. The binding energies of $\mathrm{Ag} 3 \mathrm{~d}_{3 / 2}$ and $\mathrm{Ag} 3 \mathrm{~d}_{5 / 2}$ were at 373.97 and $367.96 \mathrm{eV}$, respectively, which represent the characteristic signals of $\mathrm{Ag}$, demonstrating the presence of this noble metal.

\section{Evaluation of $\mathrm{AgNPs}$ Cytotoxicity in vitro}

The biocompatibility of AgNPs was evaluated using PMNs. As shown in Figure 4A, after incubation with different concentrations of AgNPs $(0.5 \mu \mathrm{g} / \mathrm{mL}, 1 \mu \mathrm{g} / \mathrm{mL}$, and $2 \mu \mathrm{g} / \mathrm{mL}$ ) for $4 \mathrm{~h}$, the survival rates of PMNs, measured using the CCK- 8 assay, were no statistical difference between them, while the rate in $4 \mu \mathrm{g} / \mathrm{mL}$ was significantly decreased, indicating that PMNs showed acceptable biocompatibility when the AgNPs concentration was less than or equal to $2 \mu \mathrm{g} / \mathrm{mL}$. This was further verified using the LDH release experiment shown in Figure 4B. Compared with the untreated group, the concentrations $(0.5 \mu \mathrm{g} / \mathrm{mL}, 1 \mu \mathrm{g} / \mathrm{mL}$, and 2 $\mu \mathrm{g} / \mathrm{mL}$ ) of AgNPs did not cause a significant increase in the release of $\mathrm{LDH}$, while the concentration in $4 \mu \mathrm{g} / \mathrm{mL}$ lead to a significant increase. Moreover, after incubation with AgNPs $(0.5 \mu \mathrm{g} / \mathrm{mL}, 1 \mu \mathrm{g} / \mathrm{mL}$, and $2 \mu \mathrm{g} / \mathrm{mL})$, PMNs still maintained good morphological structure, as shown in Supplementary Figure S1.

\section{Antimicrobial Evaluation of AgNPs and Isolated Human PMNs in vitro}

First, the antimicrobial capability of AgNPs was evaluated in vitro using the spread-plate method. Briefly, different concentrations $(0 \mu \mathrm{g} / \mathrm{mL}, 0.5 \mu \mathrm{g} / \mathrm{mL}, 1 \mu \mathrm{g} /$ $\mathrm{mL}$, and $2 \mu \mathrm{g} / \mathrm{mL}$ ) of AgNPs were cocultured with $1 \mathrm{~mL}$ of $1 \times 10^{5} \mathrm{CFU} / \mathrm{mL}$ bacterial fluid for $4 \mathrm{~h}$, and, as demonstrated in Figure $5 \mathrm{~A}$ and $\mathrm{B}$, the antibacterial ability of AgNPs increased as their concentration increased, showing a significant antibacterial effect at the concentration of $2 \mu \mathrm{g} / \mathrm{mL}$. Furthermore, to estimate the effect of AgNPs on the antimicrobial ability of PMNs, after pretreatment with AgNPs for $2 \mathrm{~h}$, PMNs 
A

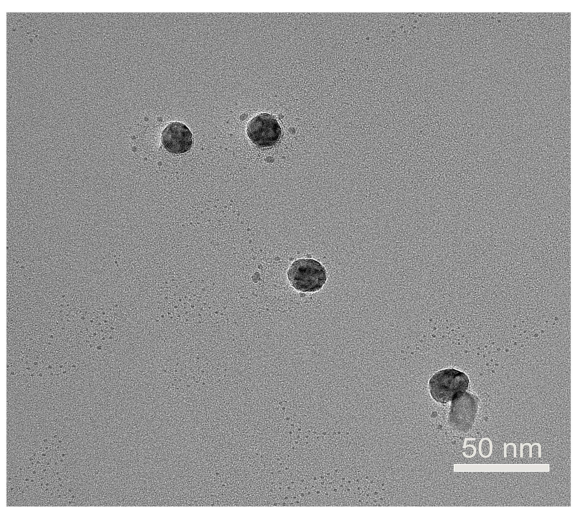

C

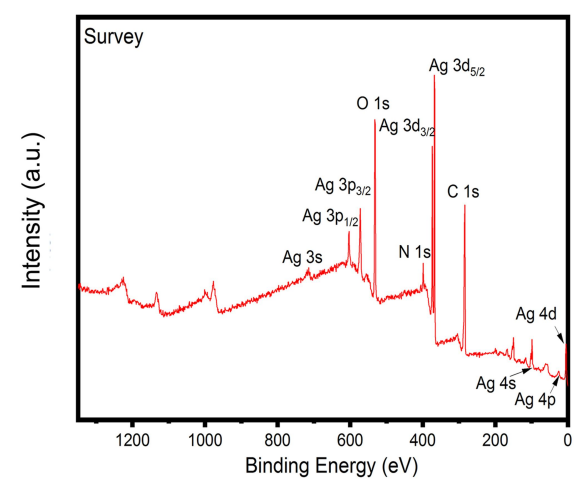

B

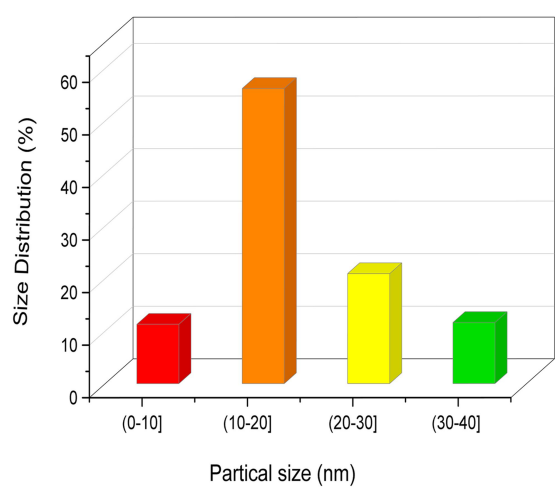

D

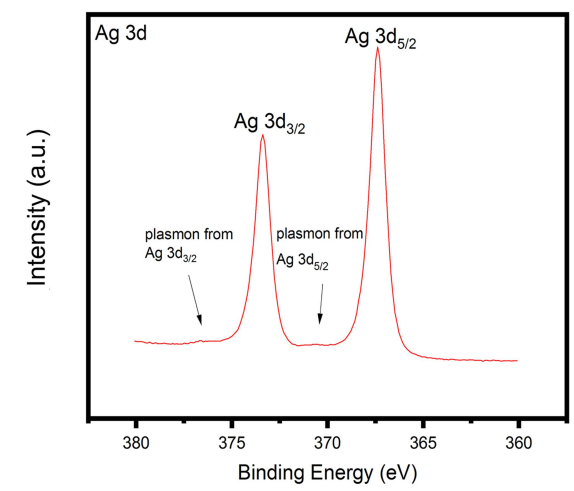

Figure 3 Characterizations of silver nanoparticles (AgNPs). (A) Transmission electron microscopy of AgNPs. Scale bar = $50 \mathrm{~nm}$. (B) The size distribution of AgNPs. (C, D) $\mathrm{X}$-ray photoelectron spectroscopy (XPS) results showing the chemical element composition and state of AgNPs.

A

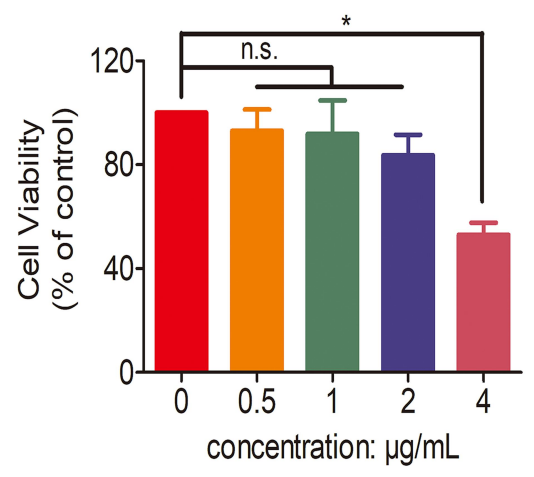

B

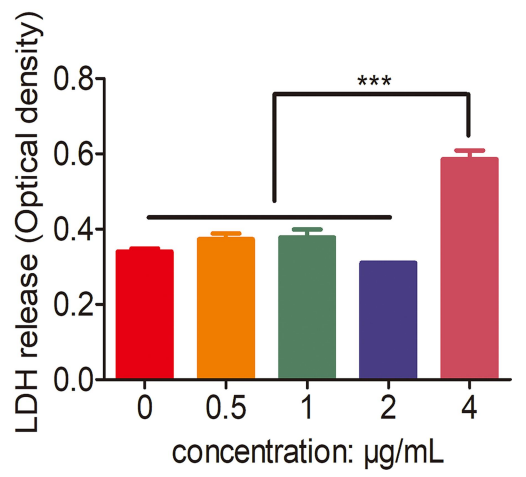

Figure 4 Cell compatibility of silver nanoparticles (AgNPs). (A) Cell viability of human polymorphonuclear neutrophils (PMNs) co-cultured with different concentrations ( 0 , 0.5 , I, 2 and $4 \mu \mathrm{g} / \mathrm{mL}$ ) of AgNPs for $4 \mathrm{~h}$. (B) Lactate dehydrogenase (LDH) release of human PMNs incubated with different concentrations (0, 0.5, I, 2 and $4 \mu \mathrm{g} / \mathrm{mL})$ of AgNPs for 4 h. n.s. represents no statistical significance, ${ }^{*} \mathrm{p}<0.05$, ${ }^{* * *} \mathrm{p}<0.00 \mathrm{I}$.

were isolated using centrifugation and incubated with bacteria. The antibacterial performance of PMNs, shown in Figure 5C and D, was inhibited by AgNPs pretreatment in a concentration-dependent manner. In summary, AgNPs exhibited strong antibacterial activity, while PMNs also exhibited certain antimicrobial capabilities. However, when treated with AgNPs, the antimicrobial capability of PMNs was obviously inhibited. 
A

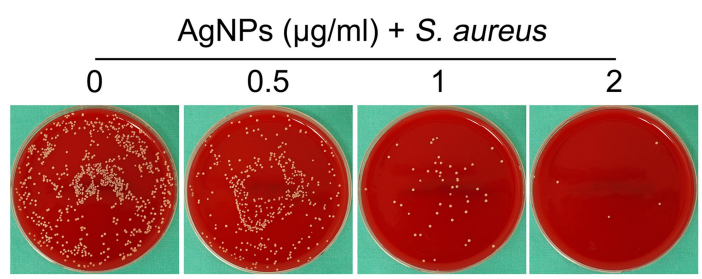

C

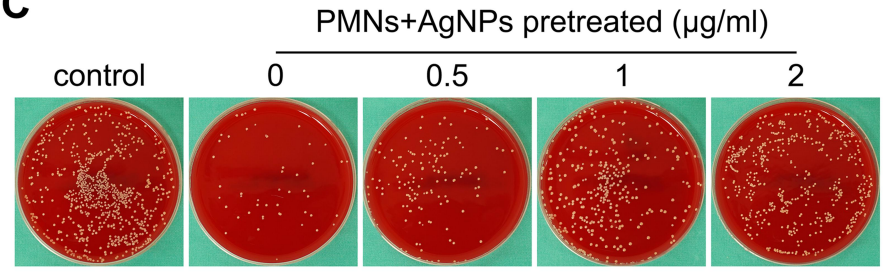

B

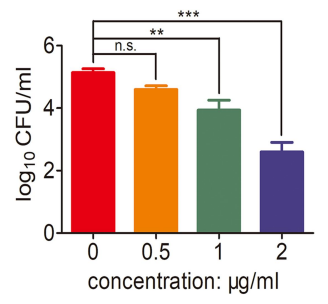

D

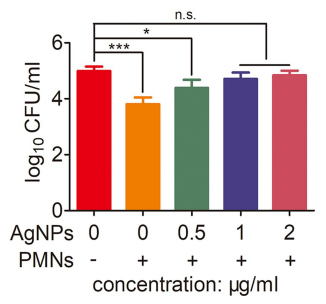

Figure $5(\mathbf{A}, \mathbf{B})$ Quantitative results obtained after treatment with different concentrations $(0,0.5, I$ and $2 \mu g / \mathrm{mL})$ of $\mathrm{AgNPs}$. (C, D) Quantitative results obtained in human polymorphonuclear neutrophils (PMNs) treated with different AgNP concentrations $(0,0.5, \mathrm{I}$ and $2 \mu \mathrm{g} / \mathrm{mL})$. n.s. represents no statistical significance, ${ }^{*} \mathrm{P}<0.05,{ }^{* *} \mathrm{p}<0.0 \mathrm{I}$, $* * * \mathrm{p}<0.001$.

\section{Antibacterial Evaluation of AgNPs in S. aureus-Infected Air Pouch Model}

The antimicrobial efficacy of AgNPs in vivo was evaluated using the $S$. aureus-infected air pouch model. As shown in Figure 6A, compared with the control group, the images of fresh soft tissues in the AgNPs $+S$. aureus group and S. aureus group showed obvious hyperemia, swelling and purulent secretions, which proved that they had a serious infectious state. To investigate the bacterial burden in vivo in each group, pathological sections were obtained to assess the inflammatory and infectious state of soft tissue. As indicated in Figure 6B, hematoxylin and eosin (H\&E) staining, used to detect the morphological changes of each group, revealed obvious acute inflammatory changes, massive neutrophil infiltration, and exudation in the $S$. aureus group. In contrast, a relatively mild degree of inflammation and less neutrophil infiltration were observed in the AgNPs + S. aureus group. Furthermore, the infectious state was confirmed using Giemsa staining (Figure 6C). A large number of bacteria were present in the $S$. aureus group, while a slightly smaller bacterial load was observed in the AgNPs + S. aureus group. To further verify the antibacterial performance of AgNPs in vivo, the bacterial burden was also evaluated using the spread-plate method, which confirmed the aforementioned results (Figure 7A and B), while the smaller bacterial counts in the AgNPs $+S$. aureus group compared with the $S$. aureus group did not reach statistical significance. Moreover, the inflammatory state of the infected air pouch was explored by measuring the level of inflammatory factors in the extracted lavage fluid. As demonstrated in Figure 7C and D, the levels of TNF- $\alpha$ and IL- 6 in the AgNPs + S. aureus group were significantly decreased compared with those in the $S$. aureus group in a dosage-dependent way.

\section{The Antibacterial Potential Was Investigated Using an ex vivo Blood-AgNPs-Bacterial Interaction Model}

After incubation for $90 \mathrm{~min}$, the antibacterial performance of the blood in presence of AgNPs was slightly superior to that of the control group, but not significantly, as demonstrated using quantitative analysis (Figure 8A and B). This indicated that the presence of AgNPs might suppress the inherent antimicrobial activity of blood. The antibacterial ability of blood mainly comes from phagocytes, including innate immune cells. Therefore, to further understand the mechanism underlying the inhibited antimicrobial ability of blood, a phagocytosis assay was performed in an ex vivo model. As the time of blood-AgNP-bacteria incubation increased, the number of bacteria phagocytized by PMNs gradually increased (Figure 8C). However, compared with the group co-cultured with bacteria alone, the phagocytic capability of PMNs began to decrease in the groups incubated with AgNPs for $15 \mathrm{~min}$, and this decrease in phagocytosis was inversely related to the concentrations of AgNPs. Furthermore, these outcomes were also verified using quantitative phagocytosis rate analysis 
A

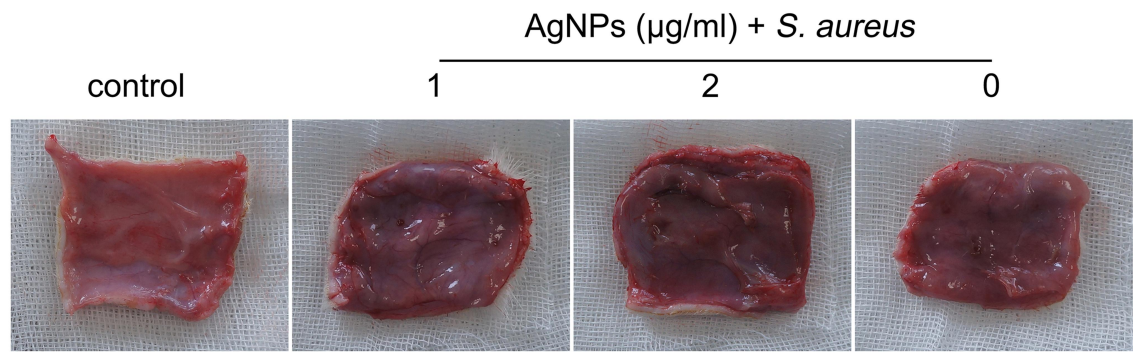

B

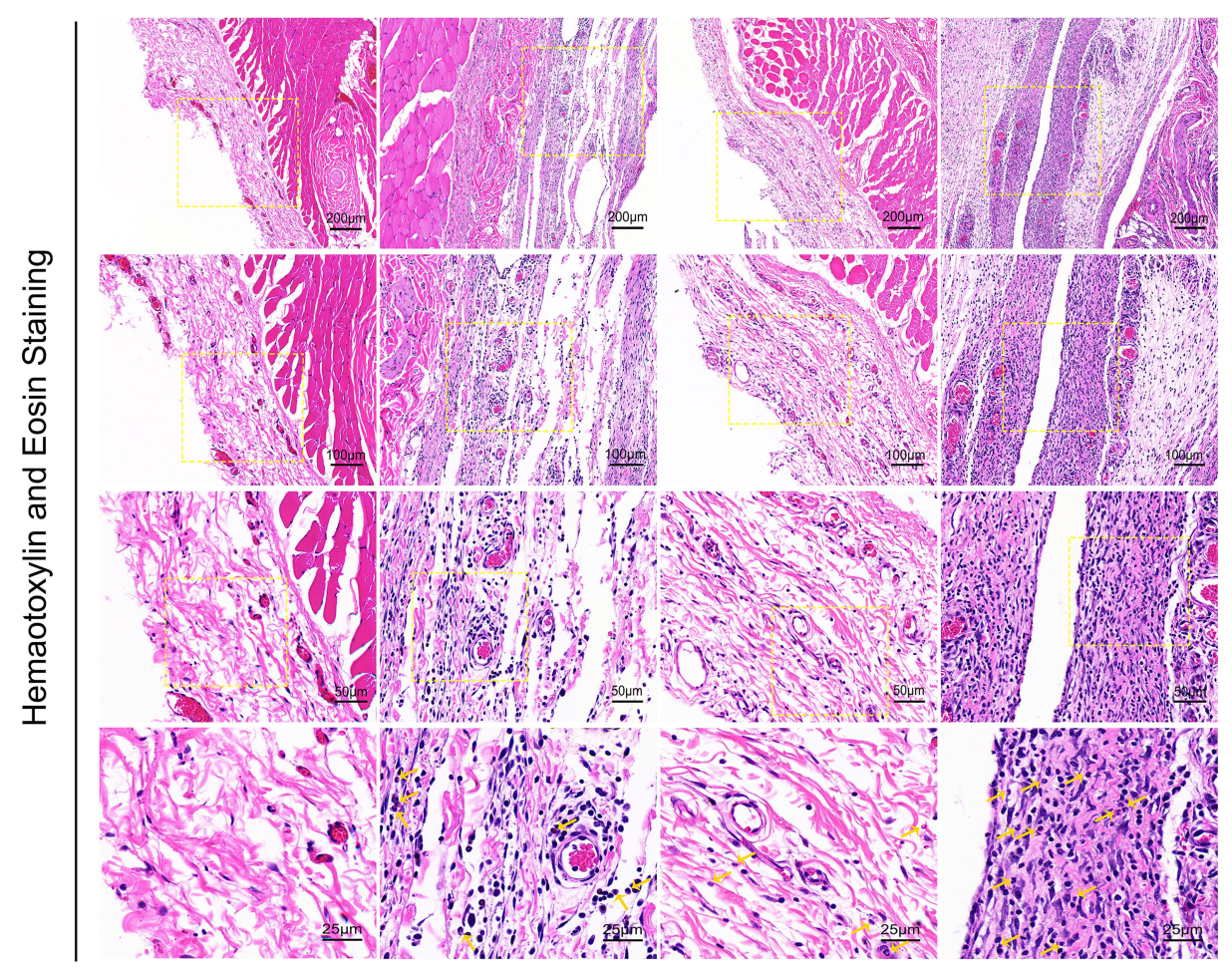

C

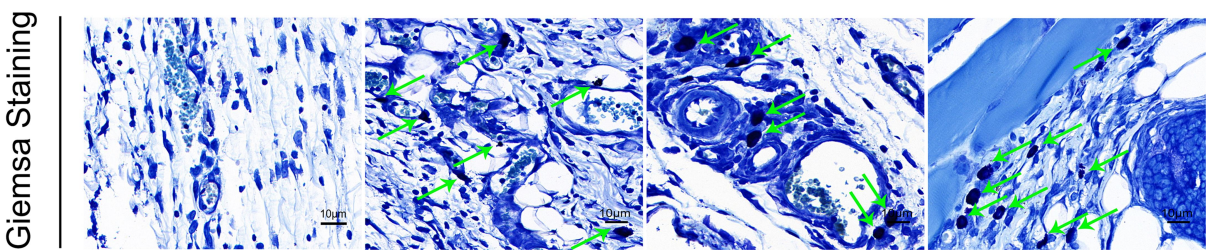

Figure 6 Histological evaluation of soft tissue of Sprague-Dawley (SD) rats at $24 \mathrm{~h}$ after the establishment of the air pouch model. (A) Representative photographs of fresh soft tissues. (B) Typical hematoxylin and eosin staining of soft tissues; the magnification increases sequentially from up to down. Yellow arrows in the images indicate polymorphonuclear neutrophil (PMNs). (C) Typical Giemsa staining of soft tissue es. Scale bar $=10 \mu \mathrm{m}$. Green arrows in the images indicate Staphylococcus aureus.

(Figure 8D). The mean phagocytosis rates at $15 \mathrm{~min}$ of incubation in the groups that received the AgNPs doses of $0,0.5,1$ and $2 \mu \mathrm{g} / \mathrm{mL}$, were $26.2 \%, 23.4 \%, 18.6 \%$ and $14.1 \%$, respectively. At $30 \mathrm{~min}$, the corresponding rates were $48.6 \%, 40.5 \%, 28.0 \%$ and $20.6 \%$, at $60 \mathrm{~min}, 72.2 \%$, $51.9 \%, 37.0 \%$ and $26.8 \%$, and at $90 \mathrm{~min}, 78.1 \%, 57.6 \%$, $43.2 \%$ and $31.8 \%$. From a statistical point of view, the
S. aureus-induced group was significantly different from the AgNPs groups during incubation for 15-90 min, and the difference became more obvious as the co-culture time increased. Considering the AgNP groups, with the increase in interaction time, the higher the concentration of AgNPs, the stronger the inhibition of phagocytosis ability of PMNs. 
A

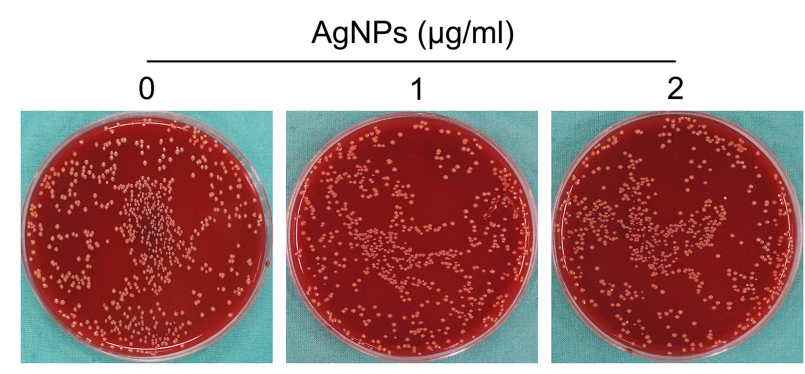

B

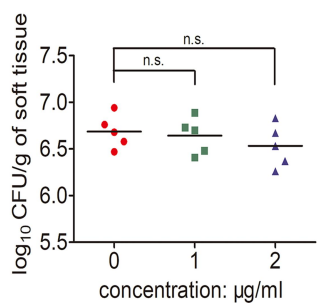

C

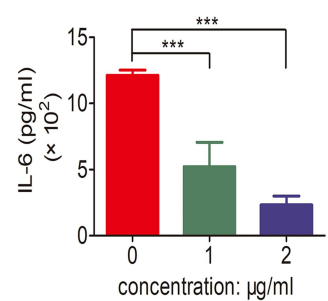

D

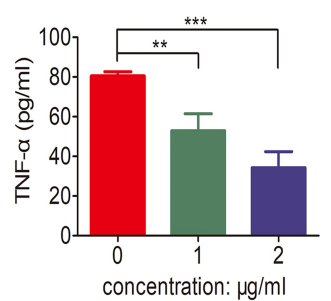

Figure 7 The antimicrobial efficacy of silver nanoparticles (AgNPs) in vivo in Staphylococcus aureus-infected air pouch. (A, B) quantitative results obtained after treatment with different concentrations (0, I and $2 \mu \mathrm{g} / \mathrm{mL}$ ) of AgNPs and bacteria in vivo. (C, D) Cytokine levels (IL-6 and TNF- $\alpha$ ) in lavage fluid extracted from Sprague-Dawley (SD) rats treated with different concentrations $(0,1$ and $2 \mu \mathrm{g} / \mathrm{mL})$ of AgNPs and bacteria. n.s. represents no statistical significance, $* * p<0.01$, $* * * p<0.00 \mathrm{I}$.

\section{PMN Lysis in Each Group}

Next, the degree of PMN lysis was further investigated. As shown in Figure 8E, the mean PMN lysis rates were $26.9 \%, 36.0 \%, 35.4 \%$, and $36.3 \%$, when the concentration of AgNPs was $0,0.5,1$, and $2 \mu \mathrm{g} / \mathrm{mL}$, respectively. Although the presence of AgNPs in the concentrations used in this experiment slightly increased the PMN lysis rate compared with that of the $S$. aureus group, there was no statistical difference between them.

\section{Inhibition of PMNs ROS and Superoxide Production}

To explore the mechanism of the AgNPs-induced reduction of the antibacterial ability of PMNs, the production of ROS and superoxide by PMNs was evaluated and the results are shown in Figure 9A-C. The fluorescent images of ROS demonstrated that the AgNPs themselves did not have a significant effect on the level of ROS production by PMNs compared with the level in the control. On the contrary, after incubation with bacteria, ROS production by PMNs significantly increased, indicating that $S$. aureus promoted ROS production of PMNs. While cocultured with PMN and bacteria, AgNPs suppressed S. aureus- induced ROS generation (Figure 9A). Furthermore, the fluorescence detected using a fluorescence microplate reader also indicated that AgNPs inhibited ROS production of PMNs, which were induced by $S$. aureus (Figure 9B). Subsequently, the results of superoxide production in each group were examined and, compared with those of the $S$. aureus-induced group, the superoxide production of PMNs treated with AgNPs and S. aureus was significantly decreased (Figure 9C). Generally, as mentioned above, PMNs ROS and superoxide production were obviously inhibited in the presence of AgNPs, and this inhibition was even more severe when higher concentrations of AgNPs were used.

\section{The Migration Ability of Human PMNs Was Suppressed by AgNPs}

Furthermore, the migration behavior of human PMNs was explored using a transwell experiment. As shown in Figure $10 \mathrm{~A}$ and $\mathrm{B}$, the number of PMNs migrating across the transwell membrane was decreased in a dosage-dependent manner in the AgNPs groups compared with the control group. Hence, the capability of PMNs to migrate to the infected site was gradually suppressed by AgNPs as their concentration increased. 
A

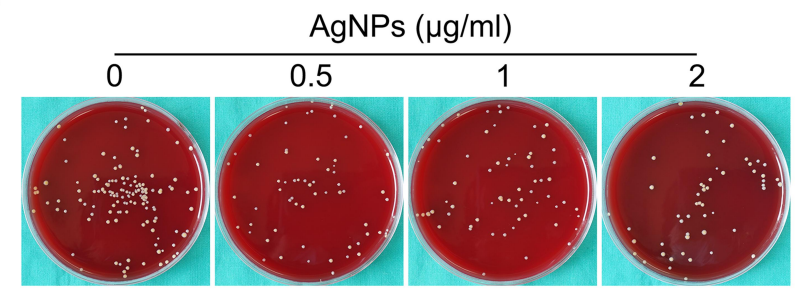

C

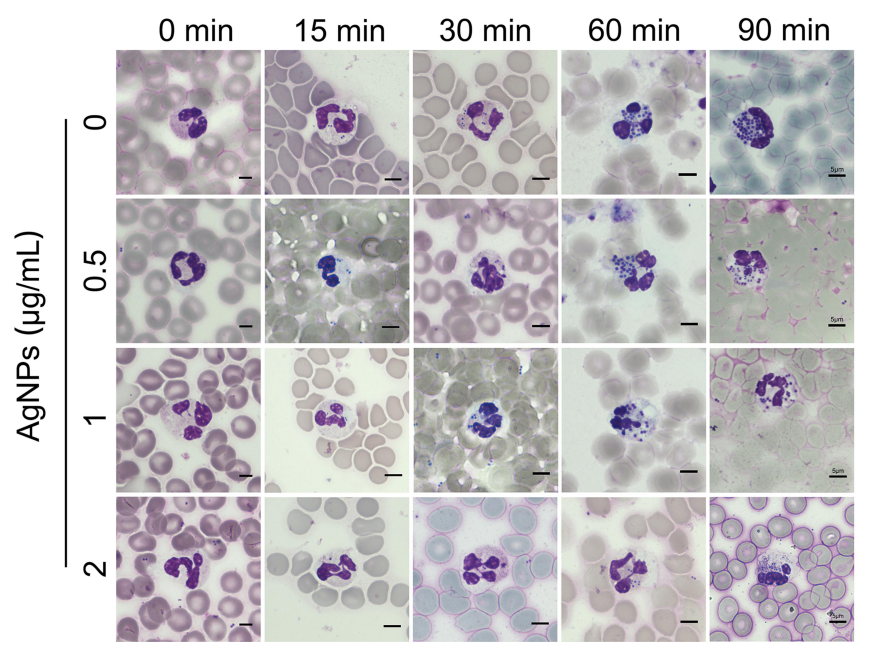

B

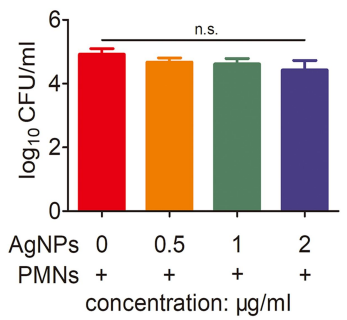

D

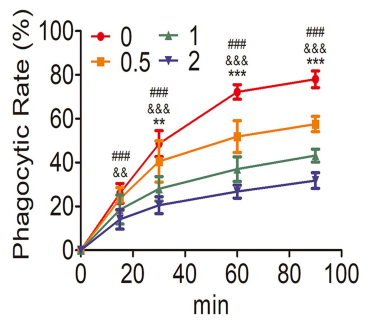

E

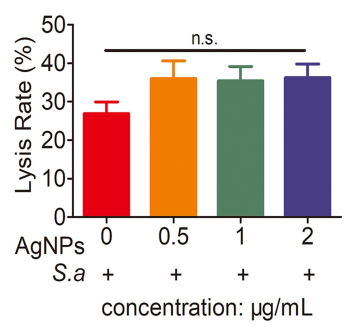

Figure 8 The antibacterial potential of silver nanoparticles (AgNPs) was investigated using an ex vivo blood-AgNP-bacterial interaction model. (A, B) Quantitative evaluation of the antibacterial efficacy against Staphylococcus aureus (S. aureus) following treatment with different concentrations $(0,0.5$, I and $2 \mu \mathrm{g} / \mathrm{mL})$ of AgNPs and S. aureus in a blood-AgNPs-bacteria system at $90 \mathrm{~min}$. (C) Representative images of the blood-AgNPs-bacteria co-culture. The round blue particles represent $S$. aureus. Scale bar $=5 \mu \mathrm{m}$. (D) Phagocytosis rate of S. aureus by human polymorphonuclear neutrophils (PMNs) in blood-AgNPs-bacteria system at $90 \mathrm{~min}$. ( $* 0.5 \mu \mathrm{g} / \mathrm{mL}$ versus $0 \mu \mathrm{g} / \mathrm{mL}, \& \mathrm{I}$ $\mu \mathrm{g} / \mathrm{mL}$ versus $0 \mu \mathrm{g} / \mathrm{mL}, \# 2 \mu \mathrm{g} / \mathrm{mL}$ versus $0 \mu \mathrm{g} / \mathrm{mL}$; **, \&\&P<0.0I; ***, \&\&\&, \#\# P<0.00I). (E) Lysis rate of human PMNs induced by $S$. aureus and different concentrations $(0,0.5, \mathrm{I}$ and $2 \mu \mathrm{g} / \mathrm{mL})$ of $\mathrm{AgNPs}$ at 2 h. n.s. represents no statistical significance.

\section{AgNPs Inhibited the Production of Pro-Inflammatory Factors, RNA Expression by PMNs}

The effects of AgNPs on PMNs pro-inflammatory cytokine secretion and the cytokine mRNA expression levels were further investigated, as demonstrated in Figure $10 \mathrm{C}-\mathrm{H}$. After the bacteria-PMNs-AgNPs system was incubated for $4 \mathrm{~h}$, IL-1 $\beta$, IL-6, and MCP-1 were significantly lower in the AgNPs $+S$. aureus group than in the $S$. aureus group, especially in the high AgNP concentration group (Figure $10 \mathrm{C}-\mathrm{E}$ ). This trend was also confirmed on the mRNA level using RT-PCR (Figure $10 \mathrm{~F}-\mathrm{H})$. These results indicated that in the presence of AgNPs, PMNs' ability to promote inflammation was severely limited.

\section{Discussion}

Neutrophils have long been considered to be extremely important in resisting the invasion of pathogenic microorganisms during the early stage of host infection. ${ }^{15,32}$ Since orthopedic biomaterials are developed as an antiinfective therapy, the optimization of these biomaterials is more focused on the improvement of their own antibacterial properties. Although neutrophils are also important in this process, few materials have been explored for their influence on the antimicrobial activity of neutrophils. ${ }^{21,22}$ As a result, biomaterials exhibiting good antibacterial activity in vitro may show a weakened or even lost antibacterial activity in vivo. ${ }^{33}$ The purpose of this study was to explore the effects of AgNPs, which have excellent antibacterial properties, on the antimicrobial efficacy of 
A

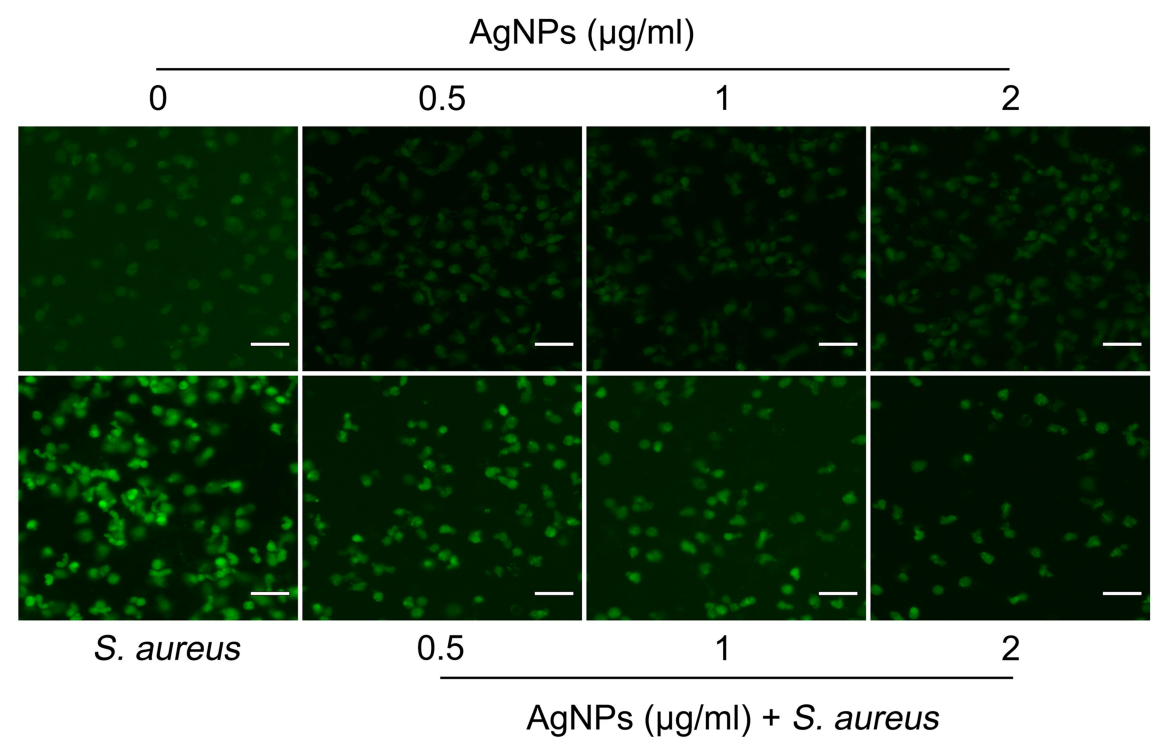

B

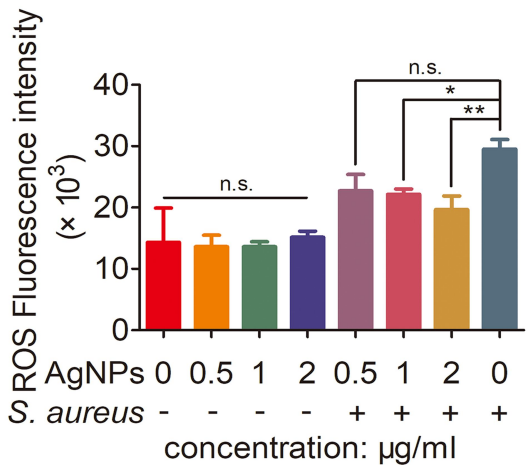

C

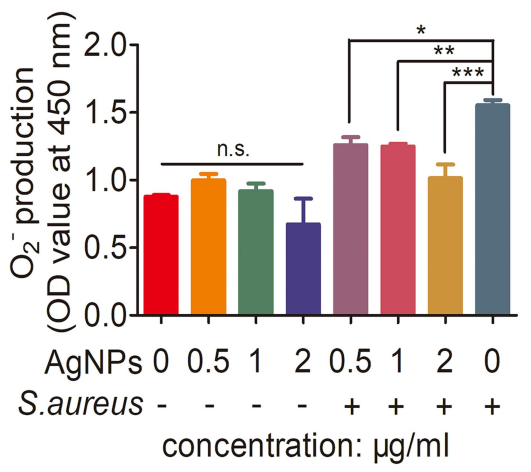

Figure 9 Inhibition of polymorphonuclear neutrophil (PMN) reactive oxygen species (ROS) and superoxide production. (A) Representative fluorescent pictures of ROS production (DCFH-DA) by human PMNs when exposed to different concentrations (0, $0.5,1$ and $2 \mu g / \mathrm{mL})$ of AgNPs with or without Staphylococcus aureus (S. aureus) at 2 h. Scale bar $=50 \mu \mathrm{m}$. (B) Fluorescence quantification measurement of DCF signals in human PMNs treated with different concentrations $(0,0.5$, I and $2 \mu g / \mathrm{mL})$ of $\mathrm{AgNPs}$ with or without $S$. aureus using a fluorescence microplate reader. $(\mathbf{C})$ Quantification of superoxide production of human PMNs. n.s. represents no statistical significance, ${ }^{*} \mathrm{p}<$ 0.05 , **p $<0.01$, *** $p<0.001$.

neutrophils in vivo and in vitro, and to further investigate the underlying mechanism.

The antibacterial efficacy of AgNPs was first evaluated in vitro. At the selected concentration, AgNPs exerted a good antibacterial effect. Previous studies have reported that AgNPs may have a negative impact on host cells and tissues at the concentration necessary to exhibit antibacterial effects. $^{34-36}$ To this end, the biosafety of AgNPs was further investigated at the chosen antimicrobial dosages. In this study, good cell biocompatibility was observed in vitro. Therefore, the concentration of AgNPs selected in this study creates a balance ideal between antimicrobial activity and biocompatibility. In addition, an infected air pouch model was established, which can be used to study the biomaterials, evaluate the tissue response to these materials under acute inflammation, and observe the antibacterial phenomenon of AgNPs in vivo. ${ }^{37}$ However, when Giemsa staining and dilution spread-plate method were used to investigate the in vivo antibacterial effect of AgNPs, the results were opposite to those obtained in vitro; that is, AgNPs did not exert their proper antibacterial activity.

Considering that AgNPs were not the only factor to exert antibacterial ability in vivo, and that the innate immune system of the host plays the most vital role in resisting bacterial invasion, ${ }^{38,39}$ the level of inflammation in the body was evaluated using lavage fluid and H\&E staining. The results showed that the presence of AgNPs decreased the inflammation level in the lavage fluid and 
A

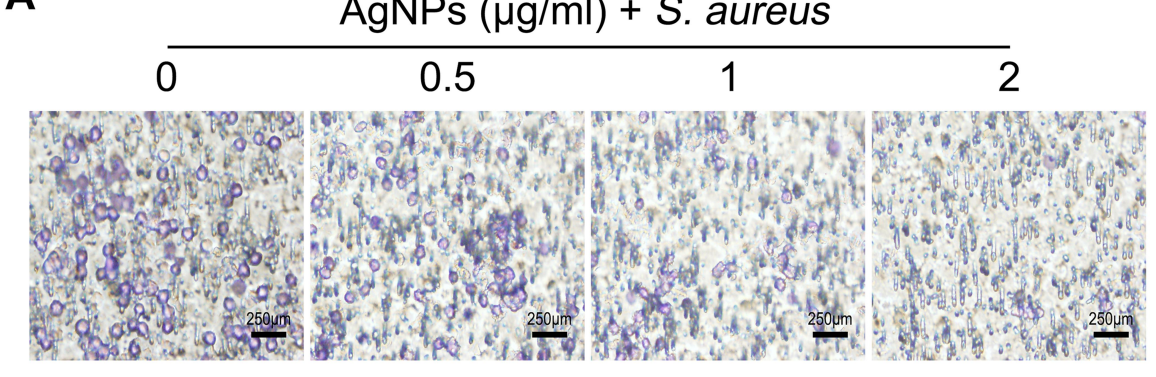

C

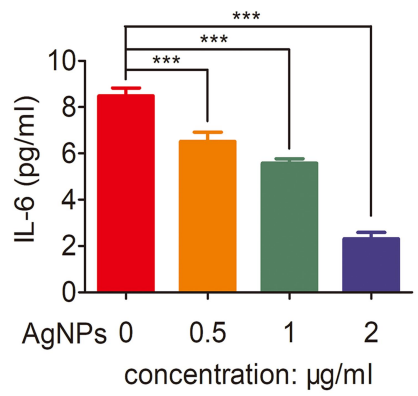

F

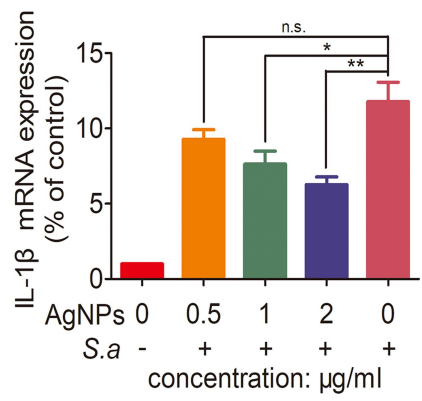

B
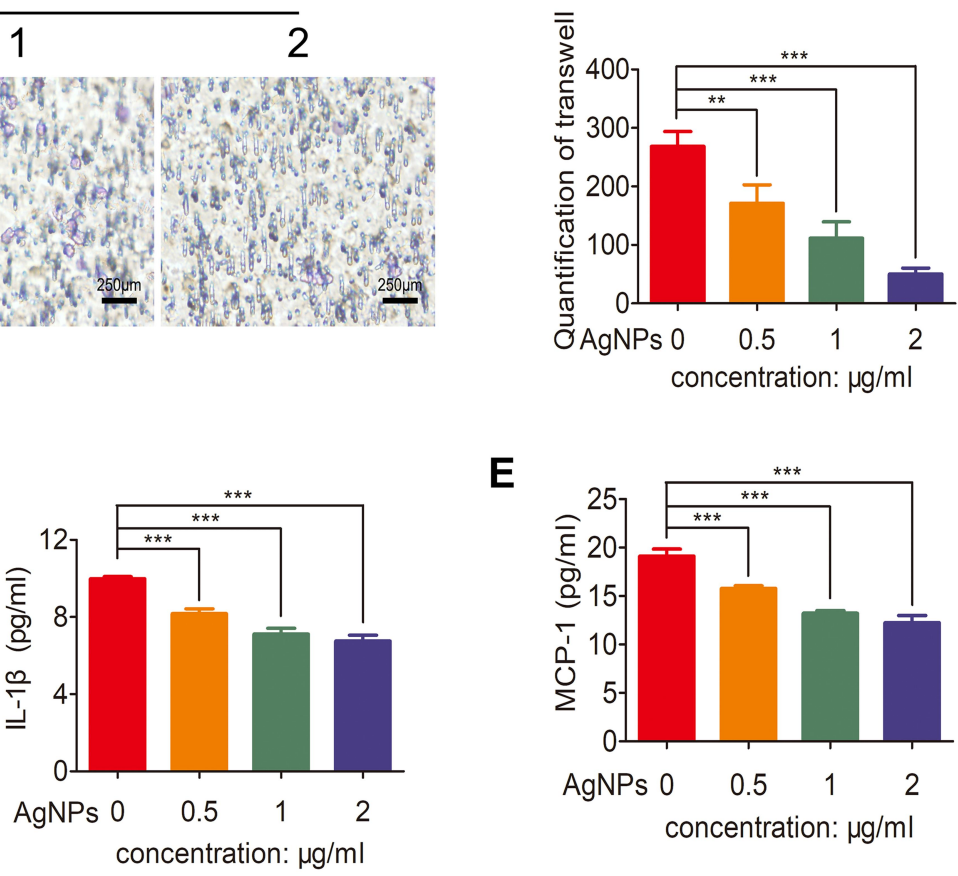

G

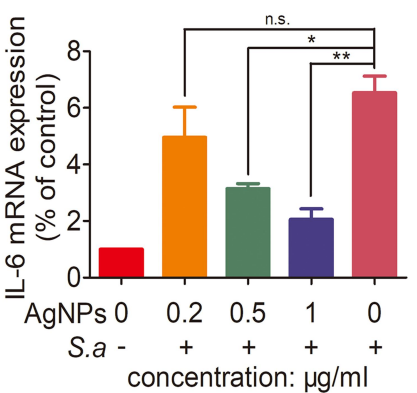

E

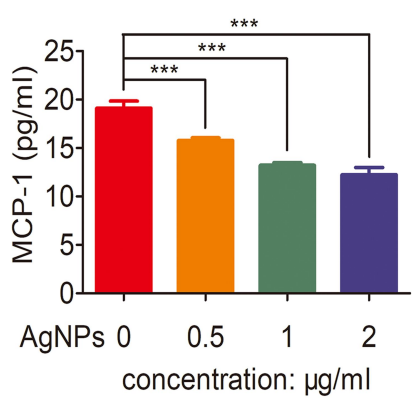

H

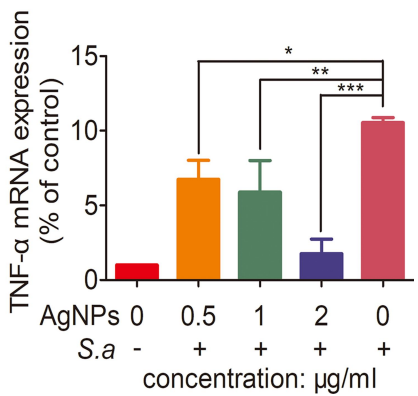

Figure 10 The effects of silver nanoparticles (AgNPs) on the migration ability of polymorphonuclear neutrophils (PMNs), their pro-inflammatory cytokine secretion and cytokine mRNA expression levels. (A) Typical images of the transwell migration experiment with cells treated with different concentrations $(0,0.5, \mathrm{I}$ and $2 \mu \mathrm{g} / \mathrm{mL})$ of $\mathrm{AgNPs}$ and Staphylococcus aureus (S. aureus). Scale bar $=250 \mu \mathrm{m}$. (B) Corresponding cell count in the transwell experiment. (C-E) Cytokine levels (IL-I $\beta$, IL-6 and MCP-I) of human PMNs incubated with different concentrations $(0,0.5$, I and $2 \mu \mathrm{g} / \mathrm{mL})$ of AgNPs and S. aureus. (F-H) Quantitative RT-qPCR of IL-I $\beta$, IL-6 and TNF- $\alpha$ expression. n.s. represents no statistical significance, ${ }^{*} p<0.05$, ${ }^{*} p<0.01$, ${ }^{* * *} p<0.001$.

the number of neutrophils around the infected soft tissue, which further proved that the changes in the results in vivo may be closely related to the suppression of the innate immune system.

It is well known that the in vivo environment is far more complex than in vitro models. When medical biomaterials are implanted into the human body, surgical operation will inevitably cause local tissue injury and bleeding, therefore there will be blood on the surface of the implant. At this point, blood will act as a medium in which biomaterials, bacteria and neutrophils can interact with each other. In order to better understand the underlying antibacterial and inflammatory phenomena in vivo, a blood-AgNP-bacteria microenvironment was constructed to explore the reasons for the difference in the in vivo and in vitro antibacterial effects of AgNPs. The antibacterial results of incubation with human blood for $90 \mathrm{~min}$ demonstrated that the antimicrobial efficacy in the AgNPs group was not significantly improved (Figure 8A), contrary to the results observed in vitro (Figure 5A), and provided an indication of the effects in vivo. Neutrophils, a type of immune cells accounting for $60-70 \%$ of circulating white blood cells, are an indispensable component of innate immunity. ${ }^{38,40}$ Therefore, the presence of blood antibacterial ability may be due to the change in the bactericidal ability of neutrophils. Phagocytosis is the most crucial antibacterial weapon 
of neutrophils, which largely determines the host's ability to resist pathogen infection. ${ }^{41,42}$ The results of Wright-Giemsa staining of blood smears confirmed that AgNPs significantly inhibited the phagocytosis efficacy of neutrophils.

When neutrophils encounter and phagocytize pathogens, phagocytosis triggers many processes in neutrophils, one of which is to transfer electrons to oxygen molecules through NADPH oxidase in the respiratory chain, resulting in the production of superoxide anions). ${ }^{43}$ Superoxide anions are the initiating switch, which will further lead to the production of ROS. $^{44}$ This process is called a respiratory burst. Both superoxide anion and ROS production is mediated by NOX2, ${ }^{45} 46$ which exerts important effects on the pathogen killing process. ${ }^{47-49}$ As shown in Figure 9A-C, AgNPs alone did not cause significant changes in the levels of ROS and superoxide in neutrophils, which was consistent with the results reported by Poirier et al. ${ }^{11}$ However, AgNPs suppressed the production of ROS and superoxide by neutrophils, when incubated with bacteria. Since NOX2 is the intermediary in the production of ROS and superoxide, we speculated that AgNPs might inhibit the activity of NOX2, thus reducing the ability of neutrophils to produce both in presence of bacteria. PI3K and AKT-1 are intracellular signal molecules closely related to ROS production when neutrophils are stimulated, which can produce high intensity of ROS through the activation of NADPH oxidase. ${ }^{50-52}$ Further research needs to be conducted to explore in depth how AgNPs affect the antibacterial performance of innate immunity and reveal the underlying molecular mechanisms.

This study mainly explored the effect of AgNPs on ROS production and phagocytosis of PMNs in the antibacterial process and its possible mechanism. It is worth noting that in addition to the bactericidal effect of PMNs through phagocytosis and ROS production, degranulation and NETs are also the other two main antimicrobial pathways of PMNs. ${ }^{16,17}$ Furthermore, when blood comes into contact with biomaterials, the complement system will be activated through the classical pathway, which can further activate the surrounding immune cells by forming membrane attack complex to resist pathogenic bacteria. ${ }^{53}$ Except for neutrophils, there are many other innate immune cells (including macrophages) that also play a vital role in protecting human body from bacterial invasion. In addition, it is worth mentioning that the human peripheral blood contains heterogeneous populations of neutrophils at different mature and active stages. ${ }^{54}$ Fraser et $\mathrm{al}^{28}$ reported that AgNPs could trigger the emergence of CD16 $6^{\text {bright }} / \mathrm{CD} 62 \mathrm{~L}^{\text {dim }}$ neutrophils, which exhibit lower ability of phagocytosis and ROS production compared with classical pro-inflammatory neutrophils. ${ }^{55}$ The factors mentioned above may be affected to varying degrees in presence of AgNPs, and may also explain the inconsistency between in vivo and in vitro results observed in this study. In this study, we only studied one kind of AgNPs, however AgNPs have different biological characteristics according to their size ${ }^{56}$ and shape ${ }^{57}$ Liz et $\mathrm{al}^{29}$ reported that $15 \mathrm{~nm}$ AgNPs induced the atypical death of neutrophils which was mainly dependent on ROS, caspase-1 and caspase-4 levels. While, in our study, there was no significant increase in the death of neutrophils and the production of ROS within the working concentration range of AgNPs, which may be attributed to the fact that the size of AgNPs and working concentration of silver nanoparticles are still within cell safe range.

Furthermore, Haase et $\mathrm{al}^{58}$ recently reported the effects of silver $(\mathrm{Ag}+)$ released by AgNPs and AgNPs on innate immune system cells, and the results indicated that the $\mathrm{Ag}$ + released from AgNPs as the component responsible for immunomodulatory activity of AgNPs on primary human leukocytes and macrophages. While AgNPs was used as a whole to explore the immunomodulatory effect only to PMNs against microbial invasion, emphasizing the overall effect in our study. We did not further distinguish between the immunomodulatory effects of $\mathrm{Ag}+$ released by AgNPs and AgNPs on PMNs, which will have a certain guiding significance for the future research.

\section{Conclusion}

We showed that AgNPs have excellent antibacterial properties in vitro; however, their antibacterial activity was greatly weakened when applied in vivo. Furthermore, a decrease in the expression of pro-inflammatory factors and the number of neutrophils recruited to inflammatory sites was observed. Moreover, the results of the ex vivo model we established to simulate the in vivo environment, demonstrated that the presence of AgNPs inhibited the antibacterial ability of the innate immune system, which was further verified by the reduced ability of PMNs to phagocytize bacteria. The results of co-culture of human neutrophils with bacteria and AgNPs indicated that AgNPs significantly inhibited the capability of neutrophils to produce ROS and superoxide as well as the migratory ability of PMNs. AgNPs are among the inorganic nanomaterials with high antibacterial properties. Studying the effects of 
AgNPs on the innate immune system's response to invasion by foreign microorganisms may give a cue, in the development or optimization of antibacterial biomaterials, actively mobilizing or even improving the antibacterial efficacy of the innate immune system might lead to great therapeutic effects.

\section{Supporting Information}

Fluorescence images of human PMNs co-cultured with different concentrations $(0.5,1$ and $2 \mu \mathrm{g} / \mathrm{mL})$ of AgNPs for $4 \mathrm{~h}$ (PDF).

\section{Abbreviations}

AgNPs, silver nanoparticles; ROS, reactive oxygen species; PMNs, polymorphonuclear neutrophils; PVPK30, polyvinylpyrrolidone K30; RPMI, Roswell Park Memorial Institute; CCK-8, Cell Counting Kit-8; LDH, lactate dehydrogenase; TRITC, Tetramethylrhodamine; Dapi, diamido-2 phenylindole dihydrochloride; CFU, colony forming units; SD, Sprague-Dawley; H\&E, hematoxylin and eosin; DCFH-DA, 2-7-dichlorodiacetate.

\section{Acknowledgment}

This work was jointly supported by the National Natural Science Foundation of China (Grant No. 31771022).

\section{Disclosure}

The authors report no conflicts of interest in this work.

\section{References}

1. Darouiche RO. Treatment of infections associated with surgical implants. $N$ Engl J Med. 2004;350(14):1422-1429. doi:10.1056/ NEJMra035415

2. Campoccia D, Montanaro L, Arciola CR. A review of the clinical implications of anti-infective biomaterials and infection-resistant surfaces. Biomaterials. 2013;34(33):8018-8029.

3. Song Z, Borgwardt L, Høiby N, Wu H, Sørensen TS, Borgwardt A. Prosthesis infections after orthopedic joint replacement: the possible role of bacterial biofilms. Orthop Rev (Pavia). 2013;5(2):65-71.

4. Khan A, Miller WR, Arias CA. Mechanisms of antimicrobial resistance among hospital-associated pathogens. Expert Rev Anti Infect Ther. 2018;16(4):269-287.

5. Cao C, Ge W, Yin J, et al. Mesoporous Silica Supported Silver-Bismuth Nanoparticles as Photothermal Agents for Skin Infection Synergistic Antibacterial Therapy. Small. 2020;16(24): e2000436.

6. Qiao Y, He J, Chen W, et al. Light-Activatable Synergistic Therapy of Drug-Resistant Bacteria-Infected Cutaneous Chronic Wounds and Nonhealing Keratitis by Cupriferous Hollow Nanoshells. ACS Nano. 2020;14(3):3299-3315.

7. Wang L, Li S, Yin J, et al. The Density of Surface Coating Can Contribute to Different Antibacterial Activities of Gold Nanoparticles. Nano Lett. 2020;20(7):5036-5042.
8. Shen X, Zhang Y, Ma P, et al. Fabrication of magnesium/zinc-metal organic framework on titanium implants to inhibit bacterial infection and promote bone regeneration. Biomaterials. 2019;212.

9. Qin H, Zhu C, An Z, et al. Silver nanoparticles promote osteogenic differentiation of human urine-derived stem cells at noncytotoxic concentrations. Int J Nanomedicine. 2014;9:2469-2478.

10. Soares T, Ribeiro D, Proença C, Chisté RC, Fernandes E, Freitas M. Size-dependent cytotoxicity of silver nanoparticles in human neutrophils assessed by multiple analytical approaches. Life Sci. 2016;145:247-254. doi:10.1016/j.lfs.2015.12.046

11. Poirier M, Simard J-C, Girard D. Silver nanoparticles of $70 \mathrm{~nm}$ and $20 \mathrm{~nm}$ affect differently the biology of human neutrophils. J Immunotoxicol. 2016;13(3):375-385. doi:10.3109/ 1547691X.2015.1106622

12. Anderson JM. Exploiting the inflammatory response on biomaterials research and development. J Mater Sci. 2015;26(3):121. doi:10.1007/ s10856-015-5423-5

13. Franz S, Rammelt S, Scharnweber D, Simon JC. Immune responses to implants - a review of the implications for the design of immunomodulatory biomaterials. Biomaterials. 2011;32(28):6692-6709. doi:10.1016/j.biomaterials.2011.05.078

14. Kolaczkowska E, Kubes P. Neutrophil recruitment and function in health and inflammation. Nat Rev Immunol. 2013;13(3):159-175. doi:10.1038/nri3399

15. Wang J. Neutrophils in tissue injury and repair. Cell Tissue Res. 2018;371(3):531-539. doi:10.1007/s00441-017-2785-7

16. Selders GS, Fetz AE, Radic MZ, Bowlin GL. An overview of the role of neutrophils in innate immunity, inflammation and host-biomaterial integration.. Regenerative Biomater. 2017;4(1):55-68. doi:10.1093/ $\mathrm{rb} / \mathrm{rbw} 041$

17. Lauková L, Konečná B. NETosis - Dr. Jekyll and Mr. Hyde in inflammation. $J$ Appl Biomed. 2018;16(1):1-9. doi:10.1016/j. jab.2017.10.002

18. Butterfield TA, Best TM, Merrick MA. The dual roles of neutrophils and macrophages in inflammation: a critical balance between tissue damage and repair. J Athl Train. 2006;41(4):457-465.

19. Nathan C. Neutrophils and immunity: challenges and opportunities. Nat Rev Immunol. 2006;6(3):173-182.

20. Li Y, Karlin A, Loike JD, Silverstein SC. A critical concentration of neutrophils is required for effective bacterial killing in suspension. Proc Natl Acad Sci U S A. 2002;99(12):8289-8294.

21. Guo G, Zhou H, Wang Q, et al. Nano-layered magnesium fluoride reservoirs on biomaterial surfaces strengthen polymorphonuclear leukocyte resistance to bacterial pathogens. Nanoscale. 2017;9 (2):875-892.

22. Yang C, Li J, Zhu C, et al. Advanced antibacterial activity of biocompatible tantalum nanofilm via enhanced local innate immunity. Acta Biomater. 2019;89:403-418.

23. Abaricia JO, Shah AH, Musselman RM, Olivares-Navarrete R. Hydrophilic titanium surfaces reduce neutrophil inflammatory response and NETosis. Biomater Sci. 2020;8(8):2289-2299.

24. Bakhsheshi-Rad HR, Ismail AF, Aziz M, et al. Co-incorporation of graphene oxide/silver nanoparticle into poly-L-lactic acid fibrous: a route toward the development of cytocompatible and antibacterial coating layer on magnesium implants. Mater Sci Eng C Mater Biol Appl. 2020;111:110812.

25. Xie K, Zhou Z, Guo Y, et al. Long-Term Prevention of Bacterial Infection and Enhanced Osteoinductivity of a Hybrid Coating with Selective Silver Toxicity. Adv Healthcare Mater. 2019;8(5):e1801465.

26. Jia Z, Xiu P, Li M, et al. Bioinspired anchoring AgNPs onto micro-nanoporous $\mathrm{TiO} 2$ orthopedic coatings: trap-killing of bacteria, surface-regulated osteoblast functions and host responses. Biomaterials. 2016;75:203-222.

27. Qin $\mathrm{H}, \mathrm{Cao} \mathrm{H}$, Zhao $\mathrm{Y}$, et al. In vitro and in vivo anti-biofilm effects of silver nanoparticles immobilized on titanium. Biomaterials. 2014;35(33):9114-9125. 
28. Fraser JA, Kemp S, Young L, et al. Silver nanoparticles promote the emergence of heterogeneic human neutrophil sub-populations. Sci Rep. 2018;8(1):7506.

29. Liz R, Simard J-C, Leonardi LBA, Girard D. Silver nanoparticles rapidly induce atypical human neutrophil cell death by a process involving inflammatory caspases and reactive oxygen species and induce neutrophil extracellular traps release upon cell adhesion. Int Immunopharmacol. 2015;28(1):616-625.

30. Merianos JJ. Quaternary ammonium antimicrobial compounds. Disinfect Sterilization Preserv. 1991;225-255.

31. Li M, Du X, Villaruz AE, et al. MRSA epidemic linked to a quickly spreading colonization and virulence determinant. Nat Med. 2012;18 (5):816-819.

32. Vaudaux PE, Zulian G, Huggler E, Waldvogel FA. Attachment of Staphylococcus aureus to polymethylmethacrylate increases its resistance to phagocytosis in foreign body infection. Infect Immun. $1985 ; 50(2): 472-477$.

33. Hook AL, Chang C-Y, Yang J, et al. Combinatorial discovery of polymers resistant to bacterial attachment. Nat Biotechnol. 2012;30 (9):868-875.

34. Rizzello L, Pompa PP. Nanosilver-based antibacterial drugs and devices: mechanisms, methodological drawbacks, and guidelines. Chem Soc Rev. 2014;43(5):1501-1518.

35. De Jong WH, Van Der Ven LTM, Sleijffers A, et al. Systemic and immunotoxicity of silver nanoparticles in an intravenous 28 days repeated dose toxicity study in rats. Biomaterials. 2013;34 (33):8333-8343.

36. Rezvani E, Rafferty A, McGuinness C, Kennedy J. Adverse effects of nanosilver on human health and the environment. Acta Biomater. 2019;94:145-159.

37. Duarte DB, Vasko MR, Fehrenbacher JC. Models of Inflammation: carrageenan Air Pouch. Curr Protocol Pharmacol. 2016;72:5.6.1-5.6.9

38. Nauseef WM, Borregaard N. Neutrophils at work. Nat Immunol. 2014;15(7):602-611.

39. Buvelot H, Posfay-Barbe KM, Linder P, Schrenzel J, Krause K-H. Staphylococcus aureus, phagocyte NADPH oxidase and chronic granulomatous disease. FEMS Microbiol Rev. 2017;41(2):139-157.

40. Caielli S, Banchereau J, Pascual V. Neutrophils come of age in chronic inflammation. Curr Opin Immunol. 2012;24(6):671-677.

41. Garg AD, Vandenberk L, Fang S, et al. Pathogen response-like recruitment and activation of neutrophils by sterile immunogenic dying cells drives neutrophil-mediated residual cell killing. Cell Death Differ. 2017;24(5):832-843.

42. Dallenga T, Repnik U, Corleis B, et al. M. tuberculosis-Induced Necrosis of Infected Neutrophils Promotes Bacterial Growth Following Phagocytosis by Macrophages. Cell Host Microbe. 2017;22:4
43. El-Benna J, Hurtado-Nedelec M, Marzaioli V, Marie J-C, GougerotPocidalo M-A, Dang PM-C. Priming of the neutrophil respiratory burst: role in host defense and inflammation. Immunol Rev. 2016;273 (1):180-193.

44. Winterbourn CC. Reconciling the chemistry and biology of reactive oxygen species. Nat Chem Biol. 2008;4(5):278-286.

45. Belambri SA, Rolas L, Raad H, Hurtado-Nedelec M, Dang PM-C, El-Benna J. NADPH oxidase activation in neutrophils: role of the phosphorylation of its subunits. Eur J Clin Invest. 2018;48(Suppl 2): e12951.

46. Klebanoff SJ, Kettle AJ, Rosen H, Winterbourn CC, Nauseef WM. Myeloperoxidase: a front-line defender against phagocytosed microorganisms. J Leukoc Biol. 2013;93(2):185-198.

47. Amulic B, Cazalet C, Hayes GL, Metzler KD, Zychlinsky A. Neutrophil function: from mechanisms to disease. Annu Rev Immunol. 2012;30:459-489.

48. Borregaard N. Neutrophils, from marrow to microbes. Immunity. 2010;33(5):657-670.

49. Nauseef WM. How human neutrophils kill and degrade microbes: an integrated view. Immunol Rev. 2007;219.

50. Douda DN, Yip L, Khan MA, Grasemann H, Palaniyar N. Akt is essential to induce NADPH-dependent NETosis and to switch the neutrophil death to apoptosis. Blood. 2014;123(4):597-600.

51. Rada B, Jendrysik MA, Pang L, et al. Pyocyanin-enhanced neutrophil extracellular trap formation requires the NADPH oxidase. PLoS One. 2013;8(1):e54205.

52. Song Z, Hudik E, Le Bars R, et al. Class I phosphoinositide 3-kinases control sustained NADPH oxidase activation in adherent neutrophils. Biochem Pharmacol. 2020;178:114088.

53. Walport MJ. Complement. First Two Parts N Eng j Med. 2001;344 (14):1058-1066.

54. Garley M, Jabłońska E. Heterogeneity Among Neutrophils. Arch Immunol Ther Exp (Warsz). 2018;66(1):21-30.

55. Sauce D, Dong Y, Campillo-Gimenez L, et al. Reduced Oxidative Burst by Primed Neutrophils in the Elderly Individuals Is Associated With Increased Levels of the CD16bright/CD62Ldim Immunosuppressive Subset. J Gerontol a Biol Sci Med Sci. 2017;72 (2):163-172.

56. Liu W, Wu Y, Wang C, et al. Impact of silver nanoparticles on human cells: effect of particle size. Nanotoxicology. 2010;4(3):319-330.

57. Pal S, Tak YK, Song JM. Does the antibacterial activity of silver nanoparticles depend on the shape of the nanoparticle? A study of the Gram-negative bacterium Escherichia coli. Appl Environ Microbiol. 2007;73(6):1712-1720.

58. Haase H, Fahmi A, Mahltig B. Impact of silver nanoparticles and silver ions on innate immune cells. J Biomed Nanotechnol. 2014;10 (6):1146-1156.
International Journal of Nanomedicine

\section{Publish your work in this journal}

The International Journal of Nanomedicine is an international, peerreviewed journal focusing on the application of nanotechnology in diagnostics, therapeutics, and drug delivery systems throughout the biomedical field. This journal is indexed on PubMed Central, MedLine, CAS, SciSearch ${ }^{\mathbb{B}}$, Current Contents ${ }^{\mathbb{B}} /$ Clinical Medicine, $^{2}$
Journal Citation Reports/Science Edition, EMBase, Scopus and the Elsevier Bibliographic databases. The manuscript management system is completely online and includes a very quick and fair peer-review system, which is all easy to use. Visit http://www.dovepress.com/ testimonials.php to read real quotes from published authors. 